Article

\title{
Simultaneous Separation of Eight Lignans in Forsythia suspensa by $\beta$-Cyclodextrin-Modified Capillary Zone Electrophoresis
}

\author{
Jun Liang *, Feng-Qiu Gong and Hui-Min Sun
}

Key Laboratory of Chinese Materia Medica (Heilongjiang University of Chinese Medicine), Ministry of Education, Harbin 150040, China; fengqiugong@163.com (F.-Q.G.); hhuiminsun@163.com (H.-M.S.)

* Correspondence: lliangjunn@163.com; Tel.: +86-4518-2195-301

Received: 5 February 2018; Accepted: 23 February 2018; Published: 26 February 2018

\begin{abstract}
The aim of the study was to develop an alternative capillary zone electrophoresis (CZE) for simultaneous determination of phillyrin (1), phillygenin (2), epipinoresinol-4-O- $\beta$-glucoside (3), pinoresinol-4-O- $\beta$-glucoside (4), lariciresinol (5), pinoresinol (6), isolariciresinol (7) and vladinol D (8) in Forsythia suspensa. The structural types of lignans 1-8 could be attributed to bisepoxylignans (1-4 and 6), monoepoxylignans (5 and 8) and cyclolignan (7). The major difficulties in the CZE separation of 1-8 could be summarization as the simultaneous presence of free lignans $(\mathbf{1}, \mathbf{2}$ and $5-8$ ) and lignan glucosides ( 3 and 4 ) and simultaneous occurrence of two pairs of isomers ( 3 and 4 as well as 5 and 7 ). Without the addition of $\beta-C D$ and methanol, the resolution of these analytes was quite poor. However, in this study, compounds 1-8 were excellently separated from each other within $15 \mathrm{~min}$ under optimized conditions with a borax running buffer ( $40 \mathrm{mM}$ borax, $\mathrm{pH} 10.30)$ containing $2 \mathrm{mM} \beta-\mathrm{CD}$ and $5 \%$ methanol $(v / v)$ at the voltage of $20 \mathrm{kV}$, temperature of $35{ }^{\circ} \mathrm{C}$ and detection wavelength of $234 \mathrm{~nm}$. Validation of the method included tests of linearity, precision, repeatability, stability and accuracy. In addition, the method offered inherent advantages such as lower analytical cost, no need of specific columns and use of small amounts of organic solvents and reagents. Finally, this green and economic CZE was successfully applied for the determination of these bioactive components 1-8 in F. suspensa fruits and its commercial extracts.
\end{abstract}

Keywords: capillary zone electrophoresis; Forsythia suspensa; lignans; $\beta-\mathrm{CD}$

\section{Introduction}

Forsythia suspensa (Oleaceae) is a perennial herb, which is widely distributed in China, Korea, Japan and many European nations [1]. The fruits of $F$. suspensa have been used as a traditional Chinese medicine for centuries, named 'Lianqiao' in Chinese, which has long been used to treat gonorrhea, erysipedas, inflammation, pharyngitis, pyrexia, tonsillitis, ulcers and other diseases. In recent years, reports about the benefits of $F$. suspensa lignans have dramatically increased [1,2]. The 'Lianqiao' could be classified into 'Qingqiao' and 'Laoqiao' according to the maturity levels of the fruits of $F$. suspensa.

Therefore, the determination of the lignans in fruits of $F$. suspensa is very necessary and several analytical methods have been used in recent years. Examples are: thin-layer chromatography (TLC) [3], high-performance liquid chromatographic (HPLC) $[4,5]$ and liquid chromatographic-tandem mass spectrometric (LC-MS) [6] techniques. However, some methods suffered from low resolutions (TLC) and large consumption of organic solvents (HPLC and HPLC-MS). Therefore, it is essential to develop a simple and sensitive analytical method for detecting and separating the lignans in fruits of $F$. suspensa.

Capillary electrophoresis (CE) is an attractive phytochemical analysis tool due to minimum requirements for sample preparation, small sample size, low reagent consumption, high separation efficiency/selectivity, and fast analysis time [7-9]. The micellar electrokinetic chromatography (MEKC) 
methods have been proposed for the analysis of diarylbutyrolactone-type, tetrahydrofuran-type, diarylbutane-type, aryltetralin-type and dibenzocyclooctene-type lignans in Phyllanthus urinaria, P. niruri and Schisandra chinensis [10,11]. Furthermore, non-aqueous and pressurized CE methods have been reported for analysis of dibenzocyclooctene-type lignans in S. chinensis for quality evaluation [12,13]. It is well-known that bisepoxylignans are the dominant components in F. suspensa. Until now, the analysis of $F$. suspensa lignans using CE has not been reported.

As mentioned above, considering the structural similarity of the investigated analytes in the present work, a $\beta$-cyclodextrin-modified capillary zone electrophoresis ( $\beta$-CD-CZE) with direct UV detection was developed for the simultaneous assay of eight bioactive components 1-8 (Figure 1) in F. suspensa and its commercial extracts for the first time and gave good results.<smiles>COc1ccc([C@@H]2OC[C@@H]3[C@H]2CO[C@H]3c2ccc(OC)c(OC)c2)cc1OC</smiles>

phillyrin, 1<smiles>COc1cc([C@@H]2OC[C@@H]3[C@H](c4ccc(OC)c(OC)c4)OC[C@H]23)ccc1O</smiles>

epipinoresinol- 4-O- $\beta$-glucoside, 3<smiles>COc1cc(C2OCC(Cc3ccc(O)c(OC)c3)C2CO)ccc1C</smiles>

lariciresinol, $5 \quad \mathrm{OH}$<smiles>COc1cc([C@@H]2OC[C@@H]3[C@H]2CO[C@H]3c2ccc(OC)c(OC)c2)ccc1O</smiles>

phillygenin, 2<smiles>COc1cc([C@H]2OC[C@@H]3[C@H](c4ccc(OC)c(OC)c4)OC[C@H]23)ccc1O</smiles>

pinoresinol-4-O- $\beta$-glucoside, 4<smiles>COc1cc([C@@H]2OC[C@@H]3[C@H]2CO[C@H]3c2ccc(O)c(OC)c2)ccc1O</smiles>

pinoresinol, 6<smiles>COc1cc(C2c3cc(O)c(OC)cc3CC(CO)[C@H]2CO)ccc1O</smiles><smiles>COc1cc(C(=O)[C@H]2[C@H](O)CO[C@H]2c2ccc(O)c(OC)c2)ccc1O</smiles><smiles>COc1cc2ccc(=O)oc2c(OC)c1O</smiles>

isofraxidin, IS

Figure 1. Chemical structures of lignans 1-8 and internal standard (IS). 


\section{Results and Discussion}

\subsection{Development of Separation Method}

In this study, compounds 1-8 were determined as phillyrin, phillygenin, epipinoresinol-4-O- $\beta$ glucoside, pinoresinol-4-O- $\beta$-glucoside, lariciresinol, pinoresinol, isolariciresinol and vladinol D, respectively. In previous reports [10], MEKC was confirmed to be useful in the analysis of lignans in different plant matrices. Thus, our preliminary electrophoresis experiments were conducted to separate compounds 1-8 using MEKC methods. The structural types of compounds 1-8 (Figure 1) could be attributed to bisepoxylignans (1-4 and 6), monoepoxylignans (5 and 8 ) and cyclolignan (7). Thus, the major difficulties in the CZE separation of compounds 1-8 could be summarized as the simultaneous presence of free lignans (1, 2 and 5-8) and lignan glucosides ( 3 and $\mathbf{4})$ and simultaneous occurrence of two pairs of isomers ( 3 and 4 as well as 5 and $\mathbf{7}$ ).

No matter which solvent described in the literature was used as a background electrolyte $[10,11]$, it did not improve the poor separation of compounds 1-8. This fact could be explained by the low-acid property and at least one hydroxy group in each core skeleton of compounds 1-8. In contrast, only methoxy and/or methylenedioxy groups occur in lignans tested in MEKC [10,11]. Thus, CZE was further attempted in this study. After many attempts, a $\beta$-CD modified CZE was finally implemented and optimized based on borax running buffer in alkali. Method development [14] was achieved by mainly optimizing $\mathrm{pH}$, borax concentrations of the buffer, $\beta-\mathrm{CD}$ and methanol for analysis.

\subsubsection{Effect of $\mathrm{pH}$}

The $\mathrm{pH}$ of the buffer has been confirmed to be a very important parameter here because only compound 1 is not charged, while compounds $\mathbf{2}-\mathbf{4}$ and $5-8$ could be charged -1 and -2 at high $\mathrm{pH}$ values, respectively. Therefore, to investigate the effect of $\mathrm{pH}$ on migration behaviors of compounds 1-8, five different $\mathrm{pH}$ values, varying from 8.85 to 10.60 (8.85, 9.50, 9.97, 10.30 and 10.60), were used based on $40 \mathrm{mM}$ borax with $2 \mathrm{mM} \beta-\mathrm{CD}$ and $5 \%(v / v)$ methanol. The results showed a gradual increase of migration time with increasing $\mathrm{pH}$ values from 8.85 to 10.60 for all of the analytes 1-8 (Figure 2A).

We observed that, if the $\mathrm{pH}$ values were lower than 9.97, the total run time was shorter within $13 \mathrm{~min}$, while the resolution for the compounds 2-6 was worse. When high $\mathrm{pH} 10.60$ was applied, the resolution between peaks $2-4$ was obviously better, whereas the resolution between peaks 5 and 6 was quite poor and co-eluted. Furthermore, the total analysis time was much longer and has moved up to $20 \mathrm{~min}$. However, a compromise was obtained at $\mathrm{pH} 10.30$, and all compounds 1-8 could be separated baseline in short time within $15 \mathrm{~min}$. Therefore, $\mathrm{pH} 10.30$ was selected for the further experiments. It is well-known that electroosmotic flow (EOF) generally increases with an increase in the $\mathrm{pH}$ of back-ground electolyte. However, it was noted here that the order of the EOF magnitude (Figure 2A) seems to be different from the general order. This may be explained by the fact that the damaged capillary column was replaced after observation of the influences at $\mathrm{pH} 9.50$.

\subsubsection{Effect of Borax Concentrations}

Borax will form a covalent complex with each compound tested. Figure $2 \mathrm{~B}$ showed the effect of borax concentrations on the separation of the compounds 1-8. Different concentrations of borax buffer ranging from 20 to $50 \mathrm{mM}$ with $2 \mathrm{mM} \beta-\mathrm{CD}$ and $5 \%(v / v)$ methanol at $\mathrm{pH} 10.30$ were used at $20 \mathrm{kV}$ as applied voltage and $35^{\circ} \mathrm{C}$, to study the effects of buffer concentrations on the migration time of the lignans 1-8. It was found that compounds $\mathbf{2}$ and $\mathbf{3}$ as well as $\mathbf{5}$ and $\mathbf{6}$ were not well separated at all using 20 and $30 \mathrm{mM}$ of borax buffer, respectively. The optimum borax concentration ensuring the separation of all compounds down to the baseline was found to be 40 and $50 \mathrm{mM}$. The $50 \mathrm{mM}$ borax buffer did increase the resolutions of compounds 6 and 7, whereas too long migration time and poor peak symmetry of compound 8 was observed. Thus, $40 \mathrm{mM}$ borax buffer was chosen for further experiments. In this study, it was also noted that the migration time of EOF was increased by increasing borax concentrations from 20 to $50 \mathrm{mM}$. 

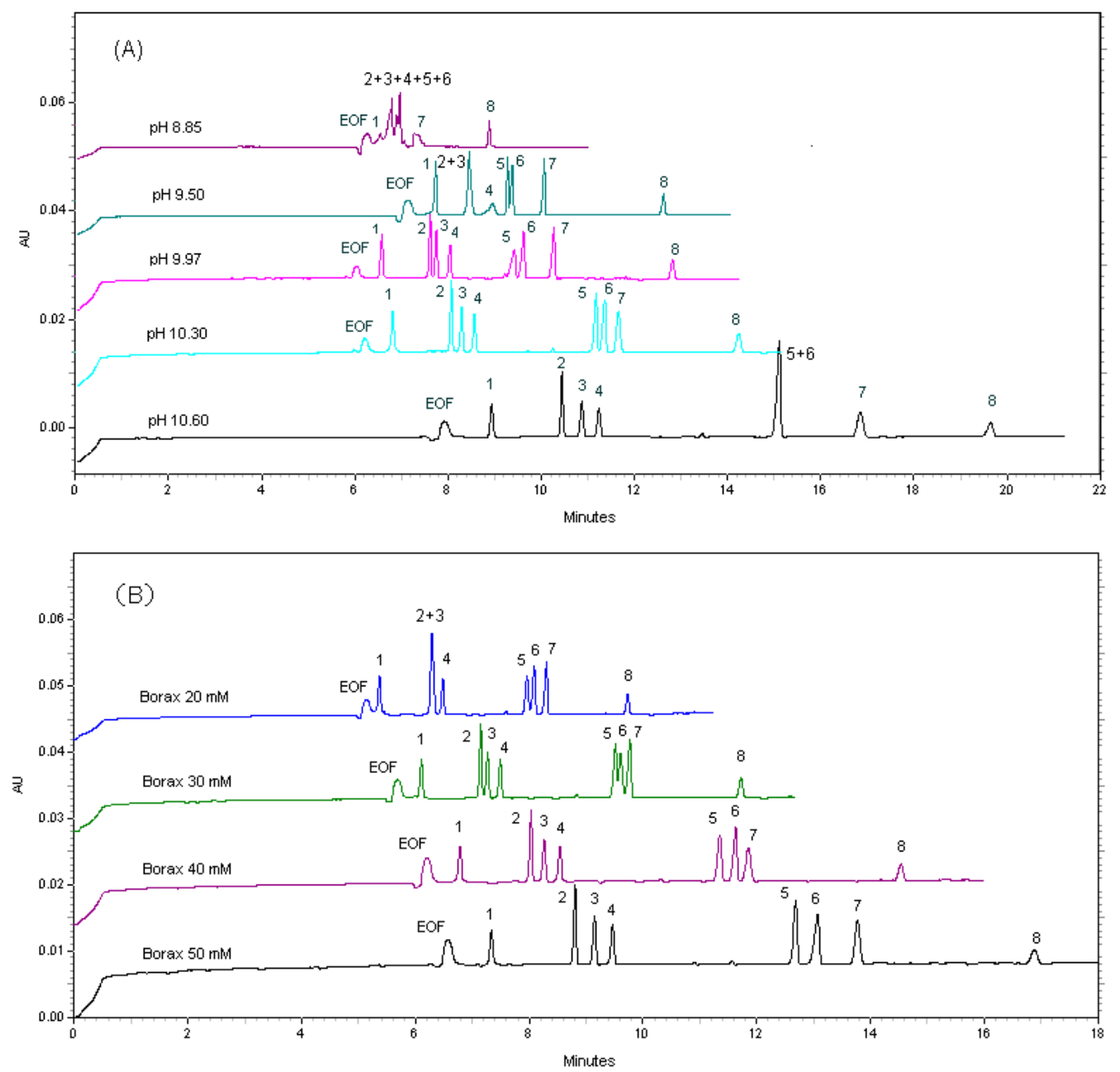

Figure 2. Effects of $\mathrm{pH}$ and buffer concentration on the migration time and separation of analytes. (A) $40 \mathrm{mM}$ borax with $2 \mathrm{mM} \beta-\mathrm{CD}$ and $5 \%(v / v)$ methanol at different $\mathrm{pH}$ vaules; (B) different concentrations of borax with $2 \mathrm{mM} \beta-\mathrm{CD}$ and $5 \%(v / v)$ methanol at $\mathrm{pH} 10.30$.

\subsubsection{Effect of $\beta-C D$}

The $\beta$-CD modified CZE method has been widely applied in enantioseparations [15]. In this study, there are two pairs of isomers ( 3 and 4 as well as 5 and 7 ) which can interact with $\beta$-CD. Thus, the effects of the addition of $\beta-C D$ on separation efficiency were investigated in $40 \mathrm{mM}$ borax with $5 \%(v / v)$ methanol at $\mathrm{pH} 10.30$. It was also noted that the mobility of compounds $\mathbf{2}-\mathbf{4}$ were obviously different before and after the addition of $\beta-C D$. As shown in Figure $3 \mathrm{~A}$, a $2 \mathrm{mM} \beta-\mathrm{CD}$ could result in the baseline separation of peaks $\mathbf{1 - 8}$, so this concentration was chosen as the optimal condition in subsequent experiments.

\subsubsection{Effect of Organic Modifiers}

The use of organic solvents such as $\mathrm{MeOH}, \mathrm{ACN}$ and isopropanol in the buffer could improve selectivity, and thus would expand the migration window [15]. According to factors mentioned above, the resolution was obtained with an electrolyte containing $40 \mathrm{mM}$ borax with $2 \mathrm{mM} \beta-\mathrm{CD}$ at $5 \%$ $\mathrm{MeOH}, 5 \% \mathrm{ACN}$ or $5 \%$ isopropanol at $\mathrm{pH} 10.30$ (Figure 3B). When $5 \% \mathrm{ACN}$ and $5 \%$ isopropanol were used, compounds $\mathbf{6}$ and $\mathbf{7}$ as well as $\mathbf{5}$ and $\mathbf{6}$ could not be separated at all, respectively. Considering resolutions, analysis time and stability of migration time, $5 \% \mathrm{MeOH}$ was the first selection. 

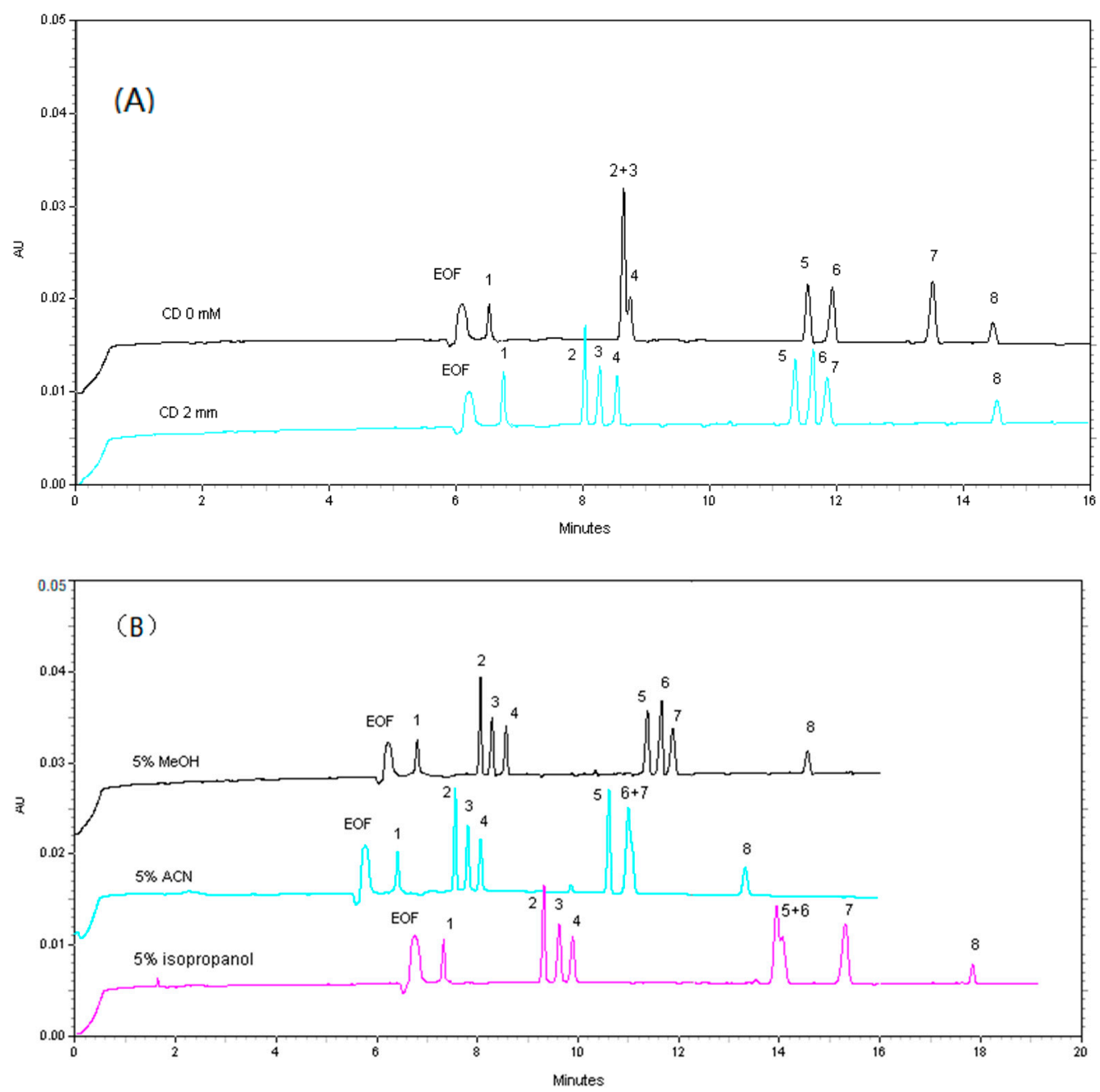

Figure 3. Effects of $\beta-C D$ and organic modifiers on the migration time and separation of analytes. (A) $40 \mathrm{mM}$ borax with different concentrations of $\beta-\mathrm{CD}$ and $5 \%(v / v)$ methanol at $\mathrm{pH} 10.30$; (B) $40 \mathrm{mM}$ borax with $2 \mathrm{mM} \beta-\mathrm{CD}$ and different organic modifiers at $\mathrm{pH}$ 10.30. Labels of compounds are the same as for Figure 2.

Based on all the factors described above, an optimal CZE condition, which was $40 \mathrm{mM}$ with $2 \mathrm{mM}$ $\beta-\mathrm{CD}$ and $5 \% \mathrm{MeOH}$ at $\mathrm{pH} 10.30$, was established for the simultaneous separation of phillyrin (1), phillygenin (2), epipinoresinol-4-O- $\beta$-glucoside (3), pinoresinol-4- $O$ - $\beta$-glucoside (4), lariciresinol (5), pinoresinol (6), isolariciresinol (7) and vladinol D (8) in F. suspensa.

\subsection{Method Validation}

To apply the method to real samples and insure the accuracy of the method, we chose isofraxidin as the internal standard (IS) compound. The linear regression between the ratios of peak areas of analytes to that of IS and the corresponding concentrations analysis were performed under the optimum conditions.

As shown in Table 1, good linearity was seen in the certain concentration range with the coefficient of determination $\left(R^{2}\right)$ higher than 0.99 for all the analytes 1-8. The limit of detections (LODs) and the limit of quantifications (LOQs) for all standard analytes were shown in Table 1 . The RSDs of migration time and peak areas (Table S1) were less than $1 \%$ and $2 \%$ for intra-day $(n=6)$ as well as less than $1 \%$ and $5 \%$ for inter-day $(n=3)$, respectively. This showed good precision for the whole method. 
Table 1. Linearity of CZE (Capillary Zone Electrophoresis) method of different analytes 1-8 ${ }^{\text {a }}$.

\begin{tabular}{cccccc}
\hline No. $^{\mathbf{b}}$ & Regression Equation $^{\mathbf{c}}$ & Linear Range $(\boldsymbol{\mu g} / \mathbf{m L})$ & LOD $(\mu \mathrm{g} / \mathbf{m L})$ & $\mathbf{L O Q}(\boldsymbol{\mu g} / \mathbf{m L})$ & ${ }^{\mathbf{d}} \boldsymbol{R}^{\mathbf{2}}$ \\
\hline 1 & $y=0.0094 x-0.117$ & $3.28-131.25$ & 0.94 & 3.28 & 0.9978 \\
2 & $y=0.0124 x-0.0963$ & $3.75-150.00$ & 1.07 & 3.75 & 0.9962 \\
3 & $y=0.0094 x-0.1055$ & $4.19-167.50$ & 1.20 & 4.19 & 0.9965 \\
4 & $y=0.0092 x-0.0868$ & $3.69-147.50$ & 1.05 & 3.69 & 0.9919 \\
5 & $y=0.0185 x-0.1889$ & $3.50-140.00$ & 1.00 & 3.50 & 0.9944 \\
6 & $y=0.0199 x-0.3224$ & $4.38-175.00$ & 1.25 & 4.38 & 0.9963 \\
7 & $y=0.0134 x-0.1248$ & $3.72-148.75$ & 1.06 & 3.72 & 0.9945 \\
8 & $y=0.0091 x-0.1021$ & $3.00-120.00$ & 0.86 & 3.00 & 0.9953 \\
\hline
\end{tabular}

${ }^{a}$ Running buffer: $40 \mathrm{mM}$ sodium borate with $2 \mathrm{mM} \beta-\mathrm{CD}$ and $5 \%(v / v)$ methanol at $\mathrm{pH} 10.30$; ${ }^{\mathrm{b}}$ Quantitated with a calibration curve at $=234 \mathrm{~nm} ;{ }^{c}$ Area ratio equation, where $y$ was the area ration between analytes and internal standard and $x$ was the concentration $(\mu \mathrm{g} / \mathrm{mL})$ of analytes; ${ }^{\mathrm{d}} R^{2}=$ correlation coefficient, $n=6$.

\subsection{Application and Recovery}

A number of biological activities of these compounds were previously reported [1,2]. The phillyrin, phillygenin, pinoresinol-4-O- $\beta$-glucoside were selected to be quantitative constituents in $F$. suspensa extract in the 2010 and 2015 editions of Chinese Pharmacopoeia. Therefore, qualitative and quantitative analysis of these characteristic constituents could play an essential role in evaluating and controlling the quality of $F$. suspensa. Here, an alternative $\beta$-CD-CZE method was readily established for determination of the bioactive compounds 1-8 in F. suspensa. Representative CZE electropherograms of reference standards as well as samples $S_{1}$ and $S_{5}$ are shown in Figure 4.

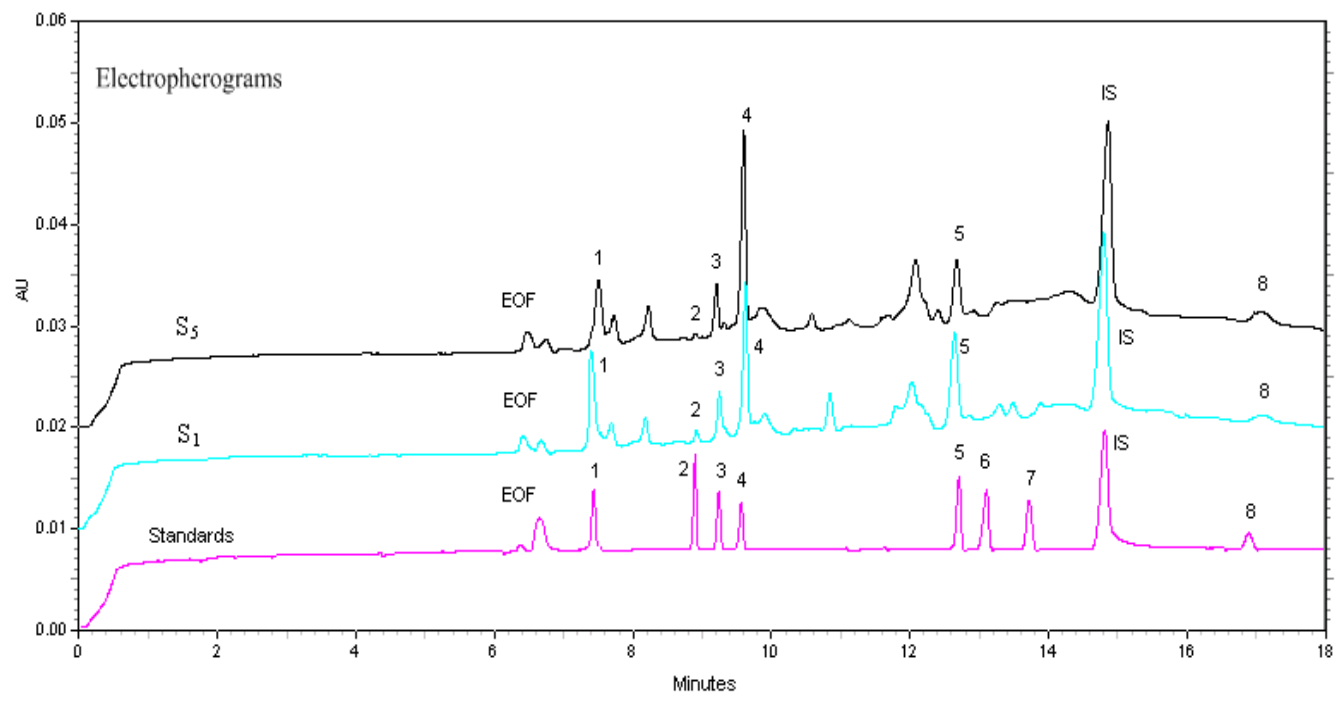

Figure 4. Electropherograms of F. suspensa extract $\left(\mathrm{S}_{1}\right)$, F. suspensa fruits $\left(\mathrm{S}_{5}\right)$ and reference standards. Labels of compounds are the same as for Figure2, IS: internal standard.

The samples $S_{1}$ and $S_{5}$ are typical commercial extracts and raw materials of $F$. suspensa, respectively. The peaks were identified by comparison of its UV spectra and the migration times with those of reference standards, and by spiking the sample solution with standards. The content of lignans 6 and 7 was too low to qualify. The amounts of compounds 1, 2, 3, 4, 5 and 8 determined in the analyzed samples have been described in Table 2. The results showed that there were remarkable differences in the contents of the lignans detected in four batches of $F$. suspensa raw materials and four batches of commercial F. suspensa extracts. These variations may explained by geographical source, cultivation, harvest, storage, and processing of the herb [4-6]. 
Table 2. Contents of compounds 1-8 in different F. suspensa extracts and F. suspensa fruits.

\begin{tabular}{|c|c|c|c|c|c|c|c|}
\hline \multirow{2}{*}{ No. } & \multirow{2}{*}{ Types } & \multicolumn{6}{|c|}{ Contents $(\mu \mathrm{g} / \mathrm{g})$} \\
\hline & & 1 & 2 & 3 & 4 & 5 & 8 \\
\hline $\mathrm{S}_{1}$ & $C E^{a}$ & $3766 \pm 135$ & $856 \pm 20$ & $2618 \pm 73$ & $6393 \pm 103$ & $3528 \pm 139$ & $1894 \pm 75$ \\
\hline $\mathrm{S}_{2}$ & $C E^{a}$ & $3942 \pm 151$ & $1693 \pm 34$ & $4039 \pm 106$ & $8972 \pm 187$ & $6603 \pm 103$ & $2904 \pm 75$ \\
\hline $\mathrm{S}_{3}$ & $C E^{a}$ & $36,887 \pm 790$ & $4707 \pm 109$ & $26,681 \pm 344$ & $70,652 \pm 978$ & $47,686 \pm 935$ & $20,869 \pm 326$ \\
\hline $\mathrm{S}_{4}$ & $C E^{a}$ & $35,529 \pm 800$ & $8825 \pm 232$ & $28,492 \pm 721$ & $71,299 \pm 1023$ & $67,462 \pm 1013$ & $18,304 \pm 289$ \\
\hline $\mathrm{S}_{5}$ & Fruits $b$ & $2009 \pm 70$ & $506 \pm 15$ & $1719 \pm 42$ & $4942 \pm 74$ & $1594 \pm 78$ & $1425 \pm 58$ \\
\hline $\mathrm{S}_{6}$ & Fruits ${ }^{b}$ & $1137 \pm 20$ & $517 \pm 14$ & $779 \pm 11$ & $1783 \pm 54$ & $761 \pm 14$ & $1104 \pm 25$ \\
\hline $\mathrm{S}_{7}$ & Fruits ${ }^{b}$ & $1110 \pm 24$ & $606 \pm 17$ & $1022 \pm 27$ & $1985 \pm 89$ & $790 \pm 29$ & $3497 \pm 167$ \\
\hline $\mathrm{S}_{8}$ & Fruits ${ }^{b}$ & - & $983 \pm 24$ & - & $611 \pm 10$ & $491 \pm 12$ & $793 \pm 15$ \\
\hline
\end{tabular}

${ }^{\mathrm{a}}$ Commercial extracts of $F$. suspensa fruits. ${ }^{\mathrm{b}}$ F. suspensa raw materials.

The recoveries were performed by adding a certain amount of mixture standards (about 50\%, 100\% and $150 \%$ of the content) to real samples. The recoveries ranged from $94 \%$ to $104 \%$ for all the samples with RSD within 4\%. The above results displayed the good reliability and accuracy for the measurement of these constituents. The recovery was calculated as follows: recovery $(\%)=100 \% \times($ amount found-original amount)/amount spiked, as shown in Table S2. Compared with other analytical methods, the developed $\beta-C D-C Z E$ possessed good linear ranges and good sensitivity. For instance, the LOQ was $3.28 \mu \mathrm{g} / \mathrm{mL}$ for phillyrin (1), which was 1.5 times lower than those from the HPLC-UV detection method [5]. Furthermore, this method showed inherent advantages such as no need for specific columns, organic solvents and reagents.

\section{Materials and Methods}

\subsection{Chemicals and Regents}

HPLC-grade methanol was purchased from Merck (Darmstadt, Germany). Sodium tetraborate $\left(\mathrm{Na}_{2} \mathrm{~B}_{4} \mathrm{O}_{7} \cdot 10 \mathrm{H}_{2} \mathrm{O}\right)$, disodium hydrogen phosphate dodecahydrate $\left(\mathrm{Na}_{2} \mathrm{HPO}_{4} \cdot 12 \mathrm{H}_{2} \mathrm{O}\right)$ and sodium hydroxide $(\mathrm{NaOH})$ were analytical grade and made in Tianjin, China. Throughout the study, deionized water was prepared by a Milli-Q water system (Millipore, Bedford, MA, USA). All other chemicals were of analytical grade. Reference standards of lignans 1-8 were isolated from the fruits of F. suspensa in our laboratory whose structures were identified on the basis of spectroscopic analysis $[5,16,17]$. The purity of each compound was determined to be $>98 \%$ by normalization of the peak areas detected by HPLC analysis.

\subsection{Electrophoretic Procedures}

Separations of lignan standards and F. suspensa samples were carried out with a P/ACE MDQ capillary electrophoresis instrument (Beckman Coulter, Fullerton, CA, USA). An integrated P/ACE 32 Karat Station (software version 4.0) was used to perform the data collection and to control the operational variables of the system. Separation was carried out in an unmodified fused silica capillary (48.5 cm $\times 50$ mmi.d., effective length $40 \mathrm{~cm}$ ) (Yongnian Optical Fiber Factory, Handan, Hebei, China). Both the capillary and samples were thermostatted to $35^{\circ} \mathrm{C}$. The samples were injected with a pressure of 0.5 psi for $5 \mathrm{~s}$. The separation voltage was raised linearly within 0.5 min from 0 to $20 \mathrm{kV}$. Detection was done with direct UV (Beckman Coulter, Fullerton, CA, USA) monitoring using a photodiode array detector at wavelength $234 \mathrm{~nm}$.

A new capillary from Yongnian Optical Fiber Factory (Handan, Hebei, China) was activated by washing consecutively with each of $0.1 \mathrm{M}$ phosphoric acid (15 min), water (10 min), $0.1 \mathrm{M}$ sodium hydroxide (15 min), and water (10 min). At the beginning of each working day, the capillary was prewashed with $0.1 \mathrm{M}$ phosphoric acid ( $2 \mathrm{~min})$, water (2 $\mathrm{min}), 0.1 \mathrm{M} \mathrm{NaOH}$ for $2 \mathrm{~min}$, water (2 min) and running buffer (2 min), respectively. Between different analyses, the capillaries were consecutively rinsed with $0.1 \mathrm{M} \mathrm{NaOH}(1 \mathrm{~min})$, water $(1 \mathrm{~min})$ and running buffer $(1 \mathrm{~min})$. 


\subsection{Standard Solutions Preparations}

For the method developments, standard stock solutions of $1.0 \mathrm{mg} / \mathrm{mL}$ were prepared in methanol, and then diluted with methanol to the appropriate concentration to establish calibration curves. The stock solutions were stored in a refrigerator $\left(+4^{\circ} \mathrm{C}\right)$.

\subsection{Sample Preparations}

The dried powder of F. suspensa fruits (100 mesh, $1 \mathrm{~g})$ in a $5 \mathrm{~mL}$ volumetric flask were extracted with $20 \%$ methanol in ultrasonic bath (pulse energy $70 \mathrm{kHz}$ ) for $30 \mathrm{~min} \times 3$ times. The total volume of extract was adjusted to $15 \mathrm{~mL}$ with $20 \%$ methanol. The mixture was centrifuged at $4000 \mathrm{rpm}$ and $4{ }^{\circ} \mathrm{C}$ for $5 \mathrm{~min}$. The supernatant was filtered by a $0.45 \mathrm{um}$ pore size filter and then used as sample solution. Before injection, $100 \mathrm{uL}$ of isofraxidin $(200 \mathrm{ug} / \mathrm{mL})$ used as internal standard was added to $900 \mathrm{uL}$ sample solution. All samples were determined in triplicate.

For F. suspensa extract analysis, $50 \mathrm{mg}$ extract was dissolved in $5 \mathrm{~mL} 20 \%$ methanol, the solution was filtered by $0.45 \mathrm{um}$ pore size filter, then $100 \mathrm{uL}$ of isofraxidin $(200 \mathrm{ug} / \mathrm{mL})$ used as internal standard was added to $900 \mathrm{uL}$ sample solution before injection.

\section{Conclusions}

This study aims to design a CZE separation as a green, simple and economic method for simultaneous determination of multiple lignans in F. suspensa. The structural types of these lignans 1-8 could be attributed to bisepoxylignans (1-4 and 6), monoepoxylignans (5 and 8) and cyclolignan (7). These compounds were also characterized by simultaneous presence of free lignans (1, 2 and 5-8) and lignanglucosides ( 3 and 4 ) and by simultaneous occurrence of two pairs of isomers (3 and 4 as well as $\mathbf{5}$ and 7). This study represents the first separation of phillyrin (1), phillygenin (2), epipinoresinol-4-O- $\beta$-glucoside (3), pinoresinol-4-O- $\beta$-glucoside (4), lariciresinol (5), pinoresinol (6), isolariciresinol (7), and vladinol D (8) using a capillary electrophoresis method. Compared with other analytical methods, this $\beta$-CD modified CZE method offered inherent advantages such as lower analytical cost, no need for specific columns and use of small amounts of organic solvents and reagents.

Supplementary Materials: The following are available online, Table S1: Intra- and inter-day variability for the assay of the 8 constituents, Table S2: Recoveries of the 6 constituents by use of the established CZE method.

Acknowledgments: This study was partly financially supported by University Nursing Program for Young Scholars with Creative Talents in Heilongjiang Province (2016209).

Author Contributions: J.L. was planned and executed the laboratory experiments. G.-F.Q. and H.-M.S. wrote this paper. All authors read and approved the final manuscript.

Conflicts of Interest: The authors declare no conflict of interest.

\section{References}

1. Piao, X.L.; Jang, M.H.; Cui, J.; Piao, X. Lignans from the fruits of Forsythia suspensa. Bioorg. Med. Chem. Lett. 2008, 18, 1980-1984. [CrossRef] [PubMed]

2. Chang, M.J.; Hung, T.M.; Min, B.S.; Kim, J.C.; Woo, M.H.; Choi, J.S.; Lee, H.K.; Bae, K. Lignans from the fruits of Forsythia suspensa (Thunb.) Vahl protect high-density lipoprotein during oxidative stress. Biosci. Biotechnol. Biochem. 2008, 72, 2750-2755. [CrossRef] [PubMed]

3. Nishibe, S.; Sasahara, M.; Miyageta, M.; Noro, Y.; Kawamura, T.; Tanaka, T. Studies on the methods for chemical identification of Forsythiae Fructus and Plantaginis Herba. J. Pharm. Soc. Jpn. 1990, 110, 453-456. [CrossRef]

4. Guo, H.; Liu, A.H.; Li, L.; Guo, D.A. Simultaneous determination of 12 major constituents in Forsythia suspensa by high performance liquid chromatography-DAD method. J. Pharm. Biomed. Anal. 2007, 43, 1000-1006. [CrossRef] [PubMed] 
5. Xia, Y.G.; Yang, B.Y.; Wang, Q.H.; Liang, J.; Wei, Y.H.; Yu, H.D.; Zhang, Q.B.; Kuang, H.X. Quantitative analysis and chromatographic fingerprinting for the quality evaluation of Forsythia suspensa extract by HPLC coupled with photodiode array detector. J. Sep. Sci. 2009, 32, 4113-4125. [CrossRef] [PubMed]

6. Cui, Y.; Wang, Q.; Shi, X.; Zhang, X.; Sheng, X.; Zhang, L. Simultaneous quantification of 14 bioactive constituents in Forsythia suspensa by liquid chromatography-electrospray ionisation-mass spectrometry. Phytochem. Anal. 2010, 21, 253-260. [CrossRef] [PubMed]

7. Wang, S.; Wu, Y.; Ju, Y.; Chen, X.; Zheng, W.; Hu, Z. On-line concentration by field-enhanced sample injection with reverse migrating micelles in micellar electrokinetic capillary chromatography for the analysis of flavonoids in Epimedium brevicornum Maxim. J. Chromatogr. A 2003, 1017, 27-34. [CrossRef] [PubMed]

8. Fung, Y.S.; Tung, H.S. Application of capillary electrophoresis for organic acid analysis in herbal studies. Electrophoresis 2001, 22, 2242-2250. [CrossRef]

9. Jiang, T.F.; Wang, Y.H.; Lv, Z.H.; Yue, M.E. Determination of kava lactones and flavonoid glycoside in Scorzonera austriaca by capillary zone electrophoresis. J. Pharm. Biomed. Anal. 2007, 43, 854-858. [CrossRef] [PubMed]

10. Kuo, C.H.; Lee, S.S.; Chang, H.Y.; Sun, S.W. Analysis of lignans using micellar electrokinetic chromatography. Electrophoresis 2003, 24, 1047-1053. [CrossRef] [PubMed]

11. Sterbová, H.; Sevcíková, P.; Kvasnicková, L.; Glatz, Z.; Slanina, J. Determination of lignans in Schisandra chinensis using micellar electrokinetic capillary chromatography. Electrophoresis 2002, 23, 253-258. [CrossRef]

12. Chen, A.; Li, C.; Gao, W.; Hu, Z.; Chen, X. Separation and determination of active components in Schisandra chinensis Baill. and its medicinal preparations by non-aqueous capillary electrophoresis. Biomed. Chromatogr. 2005, 19, 481-487.

13. Wang, J.; Chen, Y.; Lin, M.; Fan, G.; Zhao, W.; Wu, Y.; Yan, C.; Wang, J. Development of a quality evaluation method for Fructus schisandrae by pressurized capillary electrochromatography. J. Sep. Sci. 2007, 30, 381-390. [CrossRef] [PubMed]

14. Yue, M.E.; Jiang, T.F.; Liu, X.; Shi, Y.P. Separation and determination of coumarins from Cacalia tangutica by capillary zone electrophoresis. Biomed. Chromatogr. 2005, 19, 250-254. [CrossRef] [PubMed]

15. Scriba, G.K. Cyclodextrins in capillary electrophoresis enantioseparations-recent developments and applications. J. Sep. Sci. 2008, 31, 1991-2011. [CrossRef] [PubMed]

16. Kuang, H.X.; Xia, Y.G.; Yang, B.Y.; Liang, J.; Zhang, Q.B.; Li, G.Y. A new caffeyolphenylethanoid glycoside from the unripe fruits of Forsythia suspensa. Chin. J. Nat. Med. 2009, 7, 278-282. [CrossRef]

17. Liang, J.; Guo, X.D.; Xia, Y.G.; Yang, B.Y.; Wang, Q.H.; Kuang, H.X. Simultaneous determination of eight components in Forsythiae Fructus from different habitats by UPLC. Chin. J. Exp. Tradit. Med. Form. 2017, 23, 68-72.

Sample Availability: Samples of the compounds are not available from the authors.

(C) 2018 by the authors. Licensee MDPI, Basel, Switzerland. This article is an open access article distributed under the terms and conditions of the Creative Commons Attribution (CC BY) license (http:/ / creativecommons.org/licenses/by/4.0/). 